\title{
VERIFICATION AND NUMERICAL SIMULATION OF ADVANCED COMPOSITE INLET IN COMPLIANCE OF AIRWORTHINESS IMPACT REQUIREMENTS
}

\author{
Radek Doubrava ${ }^{1}$, Martin Oberthor ${ }^{1}$, Jan Raška ${ }^{1}$, Petr Bělský ${ }^{1}$, Karel Doubrava ${ }^{2}$ and Milan Dvořák ${ }^{2}$ \\ ${ }^{1}$ VZLÚ (Czech Aerospace Research Centre) \\ Beranových 130, Prague 9 - Letňany, 19905 \\ doubrava@vzlu.cz \\ ${ }^{2}$ Czech Technical University of Prague \\ Technická 4, Prague 6 - Dejvice, 16607 \\ (Karel.Doubrava, Milan.Dvorak)@fs.cvut.cz
}

Keywords: bird, hail, air inlet, FEM, impact

\begin{abstract}
Bird or hail stone strikes are an important phenomenon which must be considered during aircraft design. Most of major bird or hail strike incidents result from engine ingestion. As engines are the sole thrust providing mechanisms of an aircraft, it is critical to investigate and mitigate the effects of bird or hail strikes on engine inlets and systems to the greatest extent possible. The article presents application of test verified numerical simulation for design and full-scale test verification of advanced composite air inlet for new generation of jet trainer aircraft from point of view of high speed impact resistance. The physical bird and hail impact tests were performed at the Czech Aerospace Research Centre (VZLÚ) according to airworthiness requirements. The measurement during impact test were performed by high-speed camera, Fiber Bragg Grating (FGB) sensors and strain gauges in cooperation with Czech Technical University (CTU) in Prague. The results from full-scale bird and hail strike tests were compared with numerical simulation.
\end{abstract}

\section{INTRODUCTION}

Bird or hail stone strikes are an important phenomenon that must be taken into consideration when designing aircraft. The vulnerable parts of planes or helicopters are windshield, nose, fuselage panels, wing and empennage leading edges, rotor blades, fan blades and engines inlets [1].

International certification regulations require that all forward-facing aircraft components should be proven to withstand bird strikes to a certain level before they can be employed in an aircraft [2]. A bird impact test provides a direct method for determining bird strike resistance; however, the design of aircraft structures typically involves many iterations from design to manufacturing to testing and back, requiring that many bird impact tests to be conducted. This is not only time consuming, but also costly. Furthermore, experimental data from these tests are often narrowly focused, constituting a barrier for their direct use in refining structural design. Owing to these shortcomings, several numerical methods have been developed to simulate bird strikes to reduce the number of intermediate tests required and subsequently shorten the duration of the component design phase [3].

The testing program was established to assist in the selection of a composite material and optimised lay-up from the point of view of energy absorption from bird and hail impacts on the air inlet of a new 
generation of jet training aircraft. The tests and analysis were initiated using low impact energy tests on small test specimens [4] according the procedures given in ASTM D7136M [5] and can be expanded to high-speed impact tests on flat test specimens to verify the manufacture and performance of a complexly shaped part. The flat test specimen used in the high-speed impact resistance verification tests was designed to provide confirmation of the performance of the selected composite material and to assist in the finite element modelling of the global structure. All numerical models were calibrated on the basis of experimental results gathered with an eye toward damage initiation and propagation behaviours. Figure 1 shows building block diagram for the proposed approach.

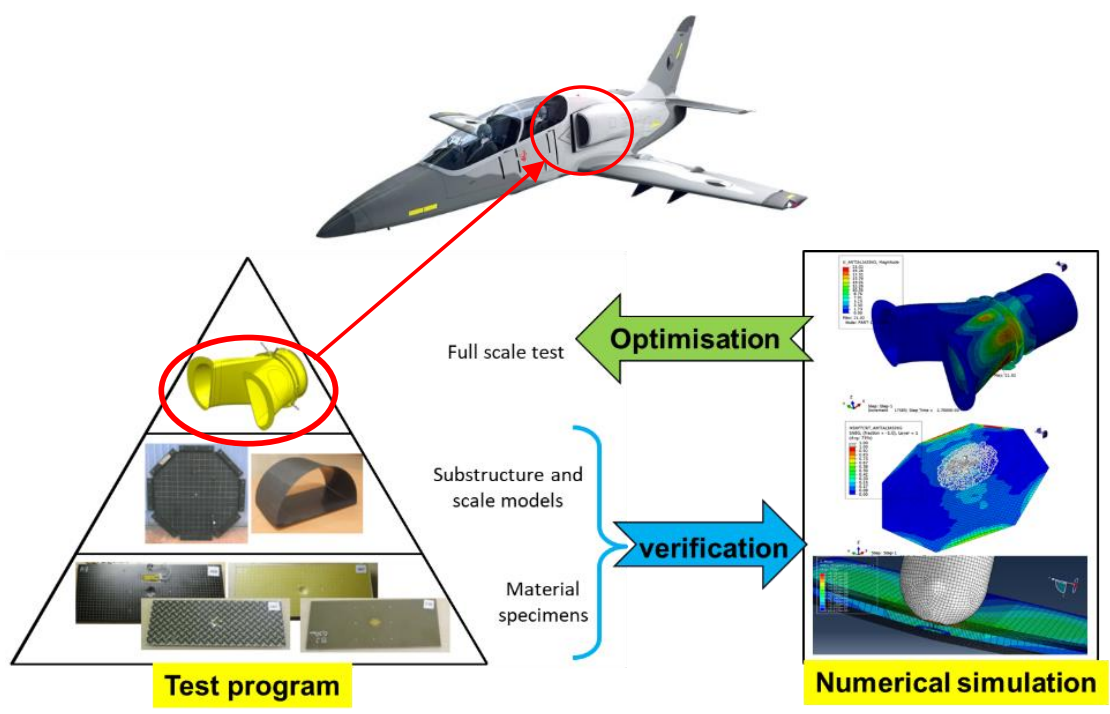

Figure 1: Building block diagram for testing and numerical simulation

\section{MATERIALS AND METHODS}

\subsection{High-speed impact tests}

Physical impact tests were performed at the Czech Aerospace Research Centre (VZLÚ) based on airworthiness requirements $[6,7]$. The required impact velocity was achieved using a properly pressurized air gun-type pressure vessel. The projectiles were accelerated by compressed air through the smooth borehole of a gun barrel up to the required velocity according to specifications. Figure 2 shows the air gun test facilities.

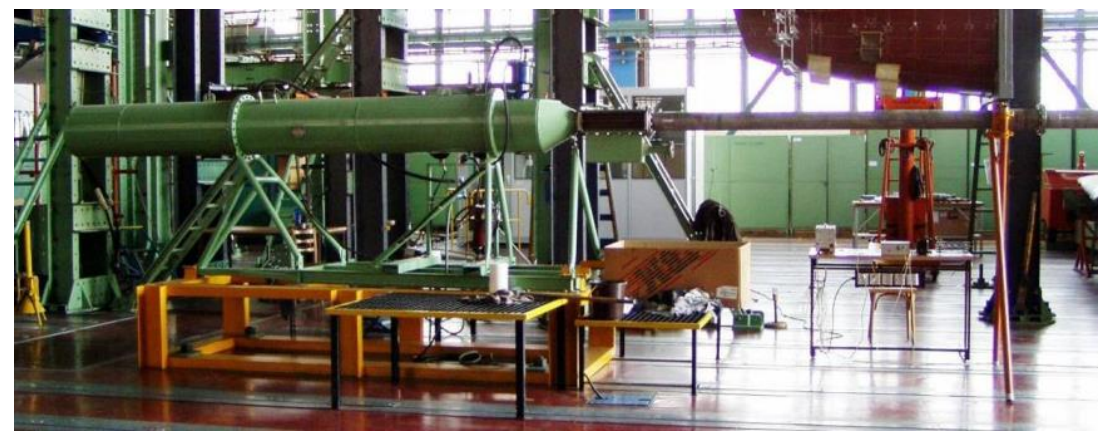

Figure 2: VZLU air gun used for high speed impact tests

The test rig (shown in Fig. 3) was designed to accommodate both perpendicular and inclined impacts for verification of numerical models on the flat test specimen. 

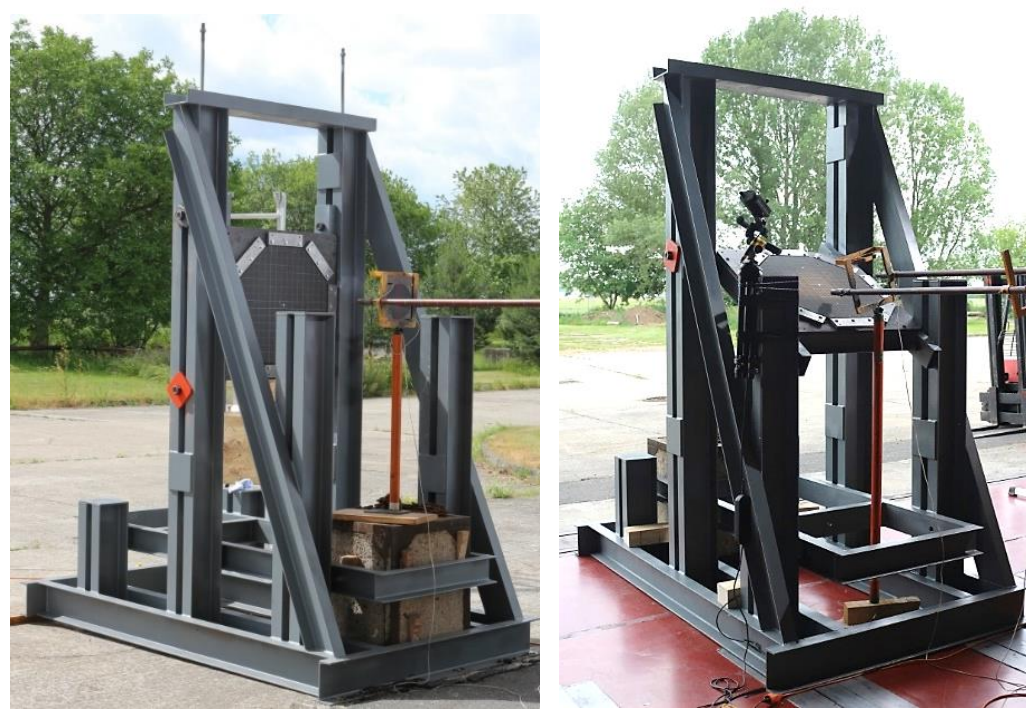

Figure 3: Test arrangement for perpendicular (left) and $30^{\circ}$ inclined (right) impacts

The test stand for test of demonstrator was designed and numerically verified from point of view of real boundary condition simulation (stiffness of fuselage) (figure 4). Full-scale inlet parts were manufactured by Aero Vodochody Aerospace company using Hexply 8552/AGP193-PW prepregs [8].
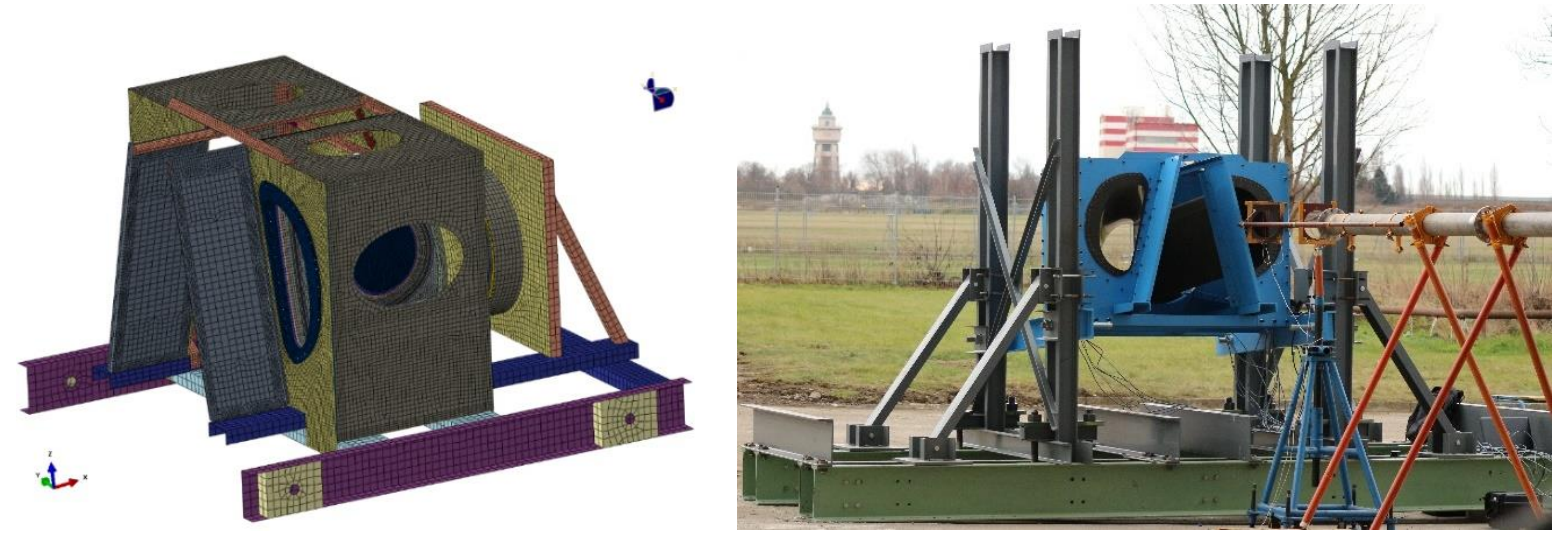

Figure 4: FE model of test stand (left) and arrangement of impact tests (right) on full scale composite air inlet

\subsection{Projectiles}

The projectile used in impact tests was a $1 \mathrm{~kg}$ (nominally) bird [6], and for the hail stone simulation, ice balls with $25 \mathrm{~mm}$ and $50 \mathrm{~mm}$ diameter were used [7] (see figure 5).
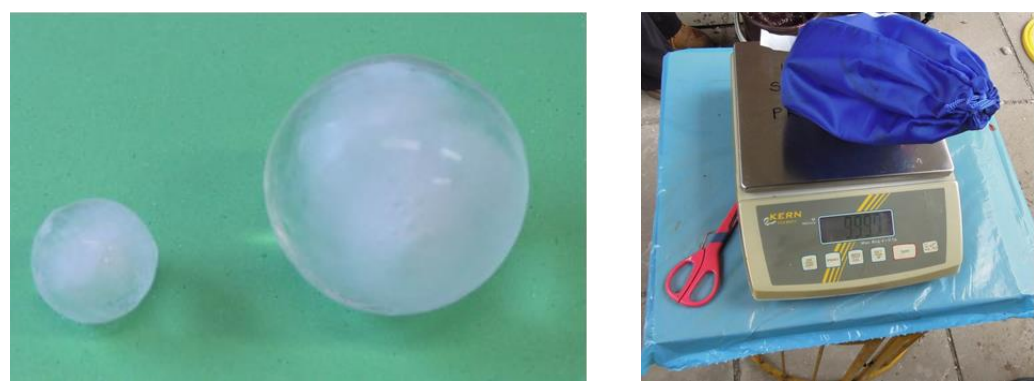

Figure 5: Ice balls $(25 \mathrm{~mm}$ and $50 \mathrm{~mm}$ ) for hail stone impact tests (left) and bird in a textile bag on a weighing machine for bird strike tests (right). 


\section{HIGH SPEED IMPACT TESTS PROCEDURE}

The high-speed impact tests for verification of numerical models were performed for perpendicular and inclined configurations on a total of 23 test specimens. The tested impact speeds ranged from 200 to $600 \mathrm{~km} / \mathrm{h}$ for bird impactor and $770 \mathrm{~km} / \mathrm{h}$ for hail stone. The perpendicular impact test set-up was selected to provide verification of the highest energy absorption capabilities of the selected material. The inclined impact tests, established at a $30^{\circ}$ angle, were selected to simulate the effects of impact on a real structure (air inlet). The high-speed camera measurement was used for analysis of displacement in impacted area on the painted grid (Figure 6 and 7) and analysis of damage initialization (figure 6 right) in comparison with NDT measurement (figure 6 centre).
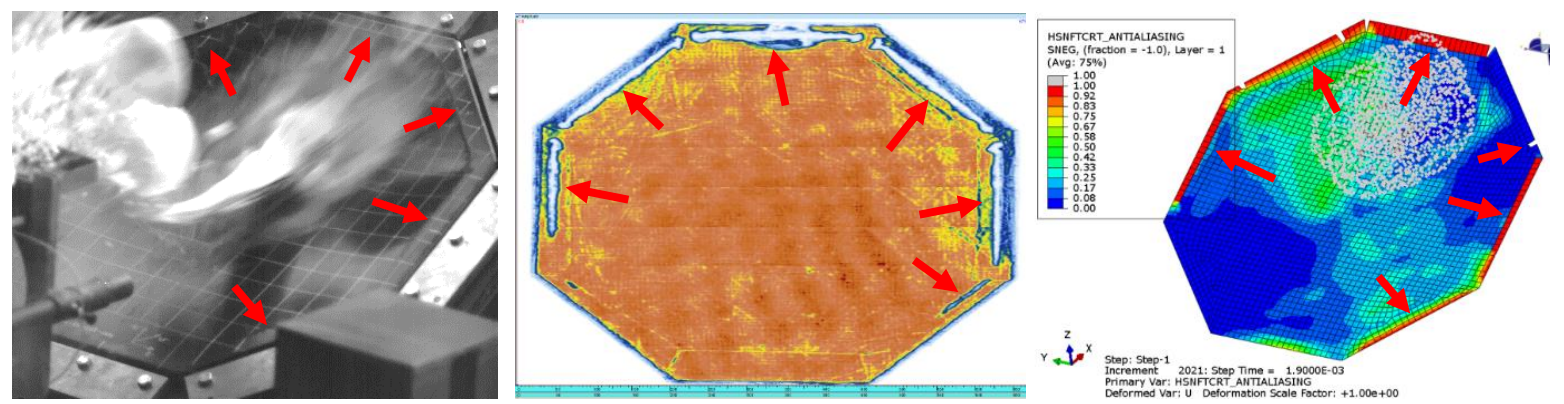

Figure 6: Example of displacement and damage analysis of flat panels from high speed camera pictures, NDT (C-scan) result and numerical simulation
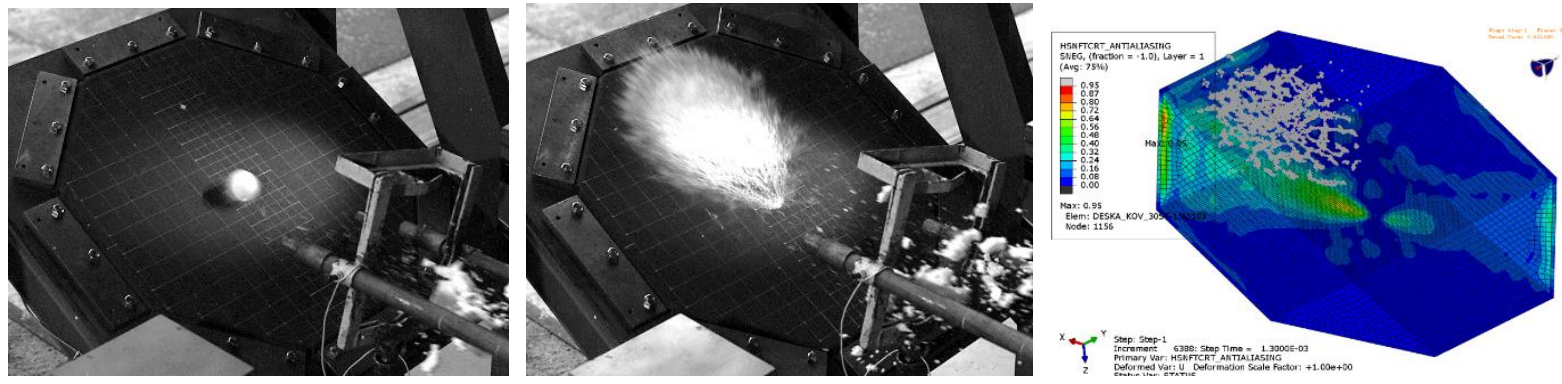

Figure 7: Example of hails stone impact analysis of flat panels from high speed camera pictures and comparison with simulation

The required impact speed for test of full scale test specimen was $594 \mathrm{~km} / \mathrm{h}(165 \mathrm{~m} / \mathrm{s})$ for bird and $770 \mathrm{~km} / \mathrm{h}(214 \mathrm{~m} / \mathrm{s})$ for hail stone [9]. The high-speed camera measurement was used for analysis of displacement in impacted area on the painted grid (Figure 8 left). The measurement by Fiber Bragg Grating (FBG) sensors (figure 8 left) and strain gauge measurement were performed by Czech Technical University (CTU) in Prague (figure 8 right) [10].
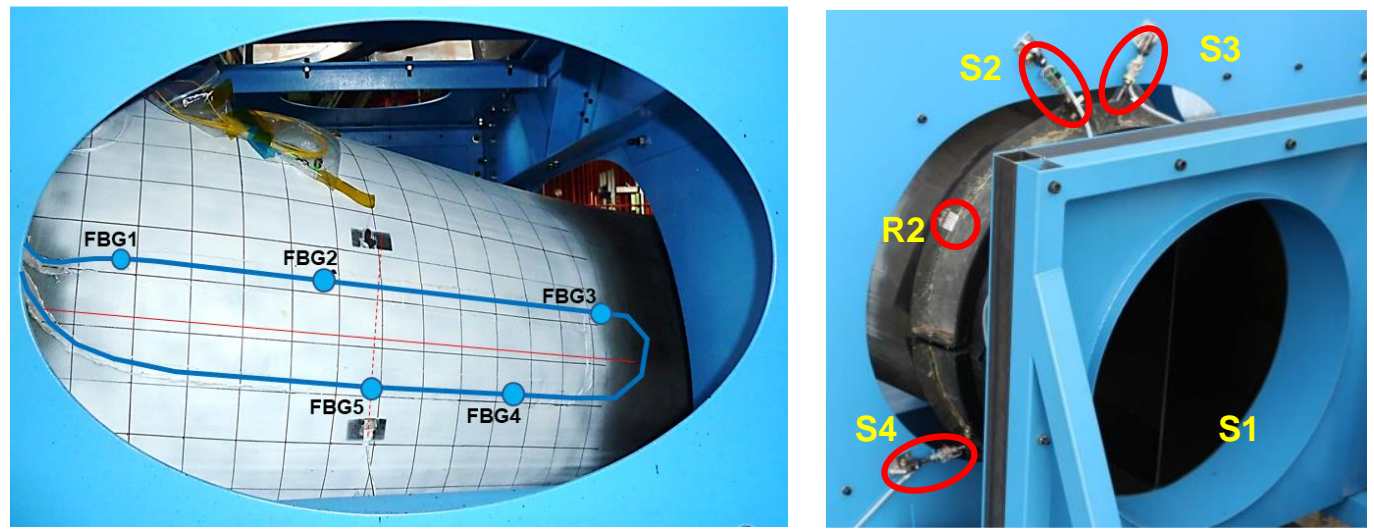

Figure 8: FBG (left) and strain gauge measurement (CTU) [10] 


\section{NUMERICAL SIMULATION}

The numerical simulation was focused from point of view of high energy impact on birds strike test simulation.

A bird strike is a high-velocity impact in which materials with a huge difference in properties (a bird is a soft impacting material compared to the stiff material of the target aircraft body) come into contact with each other, resulting in nonlinear material behavior, high strain rates, and extremely large deformations. Nonlinear Finite Element (FE) software has the capability to predict the loads and deformations of both the bird projectile and the complex aircraft component being impacted within acceptable levels of accuracy. In high-velocity impacts, the pressure on the bird tissues severely exceeds their limits, causing the bird material to behave like a fluid [3].

Thus, the bird material can be described by the so-called "elastic-plastic hydrodynamic" material model. The hydrodynamic material model is defined in ABAQUS [12] by a tabulated equation of state using Hugoniot curves for water-like homogenized bird materials $[13,14]$. The bird nodes were charged with an initial velocity, and a combination of tensile failure and shear failure criteria was used.

The geometry of the projectile (bird) was idealized as a $60 \mathrm{~mm}$ long cylinder with two hemispheric ends having a radius of $60 \mathrm{~mm}$. The bird geometry used in the simulation reflects the general geometry of the bird projectile used in the physical experiments. The geometry of the bird model was meshed by 10,770, C3D8R 8-node linear brick elements with conversion to particle elements (SPH - Smoothed Particle Hydrodynamics) [10]. The density of the bird material in the model for the defined volume was established to reflect the weight of the birds used in the physical tests.

The FE simulations were performed using the ABAQUS FE software package [13]. An explicit solver with double precision was used for the analysis. The aim of this analysis was to tune unknown inputs and computational parameters to obtain the same behavior as observed in the physical tests, namely energy absorption and damage. The same setup of this numerical model can then be used for the analysis of the entire aircraft structure.

From the point of view of the damage analysis of a composite material, the Hashin's damage material model was used. The expressions for the Hashin tensile fibre failure criteria [15], after some bidimensional simplifications $\left(\sigma_{3}=\tau_{13}=0\right)$, are shown below in equations (1) and (2). Damage initiation occurs when either of these indices exceeds 1.

$$
\begin{aligned}
& \left(\frac{\sigma_{1}}{\sigma_{1 u}^{t}}\right)^{2}+\left(\frac{\tau_{12}}{\tau_{12 u}}\right)^{2}=1 \quad\left(\sigma_{1}>0\right) \\
& \left(\frac{\sigma_{2}}{\sigma_{2 u}^{t}}\right)^{2}+\left(\frac{\tau_{12}}{\tau_{12 u}}\right)^{2}=1 \quad\left(\sigma_{2}>0\right)
\end{aligned}
$$

where $\sigma_{1}$ is the stress in direction $1 ; \sigma_{1 u}$ is the ultimate tensile stress in direction 1 (maximum tensile longitudinal strength); $\sigma_{2}$ is the stress in direction $2 ; \sigma_{2 u}$ is the ultimate tensile stress in direction 2 (maximum tensile transversal strength); $\sigma_{3}$ is the stress in direction $3 ; \tau_{13}$ is the shear stress in plane 13 ; $\tau_{12}$ is the shear stress in plane 1-2; and $\tau_{12 u}$ is the ultimate shear stress in plane 1-2 (maximum shear strength in plane 1-2).

Table 1 summaries the material properties used in Hashin's model of energy criterion in ABAQUS for damage evolution, as defined in $[8,11]$. 


\begin{tabular}{lccc}
\hline & $\begin{array}{c}\sigma_{1 \mathrm{ut}} \\
{[\mathrm{MPa}]}\end{array}$ & $\begin{array}{c}\sigma_{2 \mathrm{ut}} \\
{[\mathrm{MPa}]}\end{array}$ & $\begin{array}{c}\tau_{12 \mathrm{u}} \\
{[\mathrm{MPa}]}\end{array}$ \\
\hline Hashin - damage model & 880 & 880 & 84 \\
\hline
\end{tabular}

Table 1: Input material properties for the Hashin damage model $[8,11]$

To simulate the composite structure, 4-node shell elements (S4R) with a mesh size of $10 \mathrm{~mm}$ were used. Figure 9 shows FE model of flat test panels used for verification and calibration of material model and FE model of full scale air inlet.
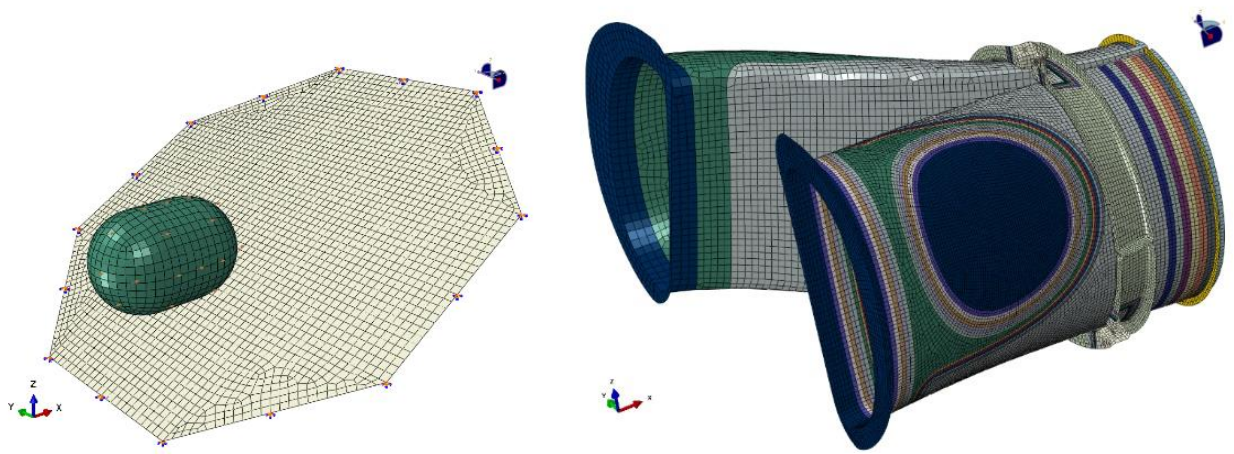

Figure 9: FE model of flat test specimen with model of bird impactor (left) and FE model of air inlet (right)

The design of air inlet was verified and optimised with target of no damage when required of bird or hail stone impact speed. Maximal value of Hashin tensile fibre criterion from numerical simulation was 0.62 (damage initiation occurs when the value exceeds 1 ).

\section{COMPARISON OF RESULTS}

The real speed achieved during the tests of full scale air inlet was $629 \mathrm{~km} / \mathrm{h}$ for bird and $789 \mathrm{~km} / \mathrm{h}$ for hail stone. The results from the numerical simulation were compared with the experiment results for bird strike test.

Figure 10 shows comparison of displacement measurement from high speed camera pictures and result of numerical simulation.
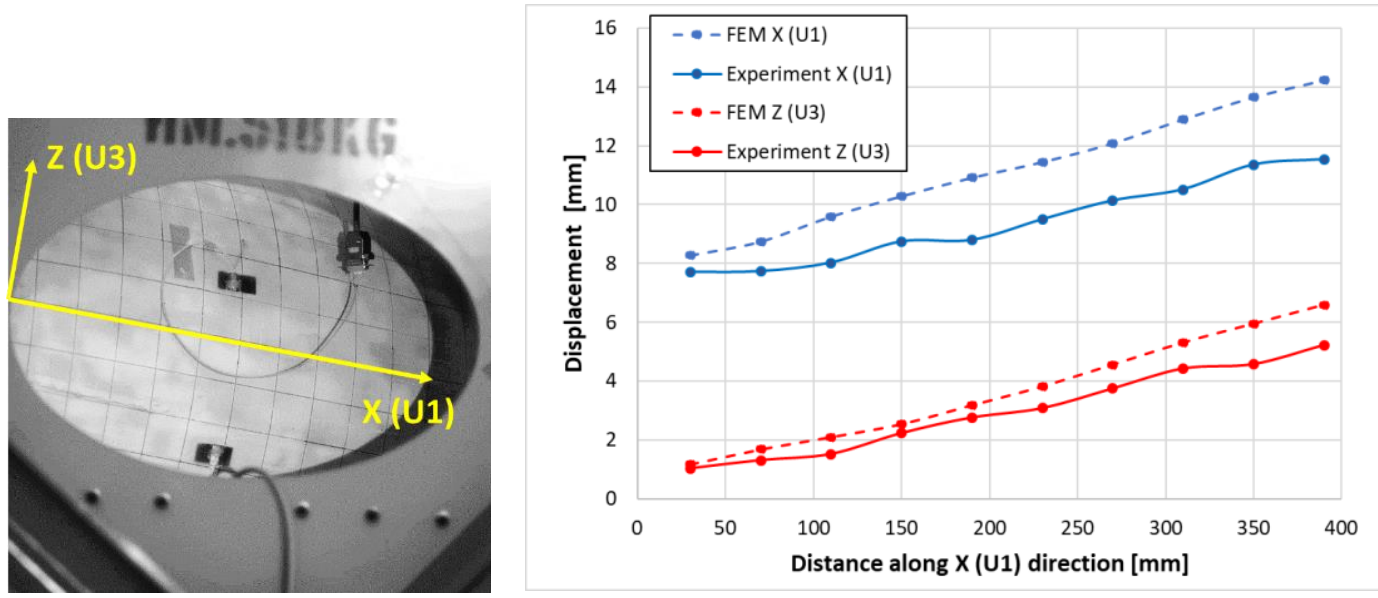

Figure 10: Comparison between qualitative measurement of displacement from high speed camera picture (full lines) and numerical simulation (dotted lines) for time impact $3 \mathrm{~ms}$

Figure 11 shows comparison between experiment and numerical simulation on strain gauge measurement on attachment rods. 

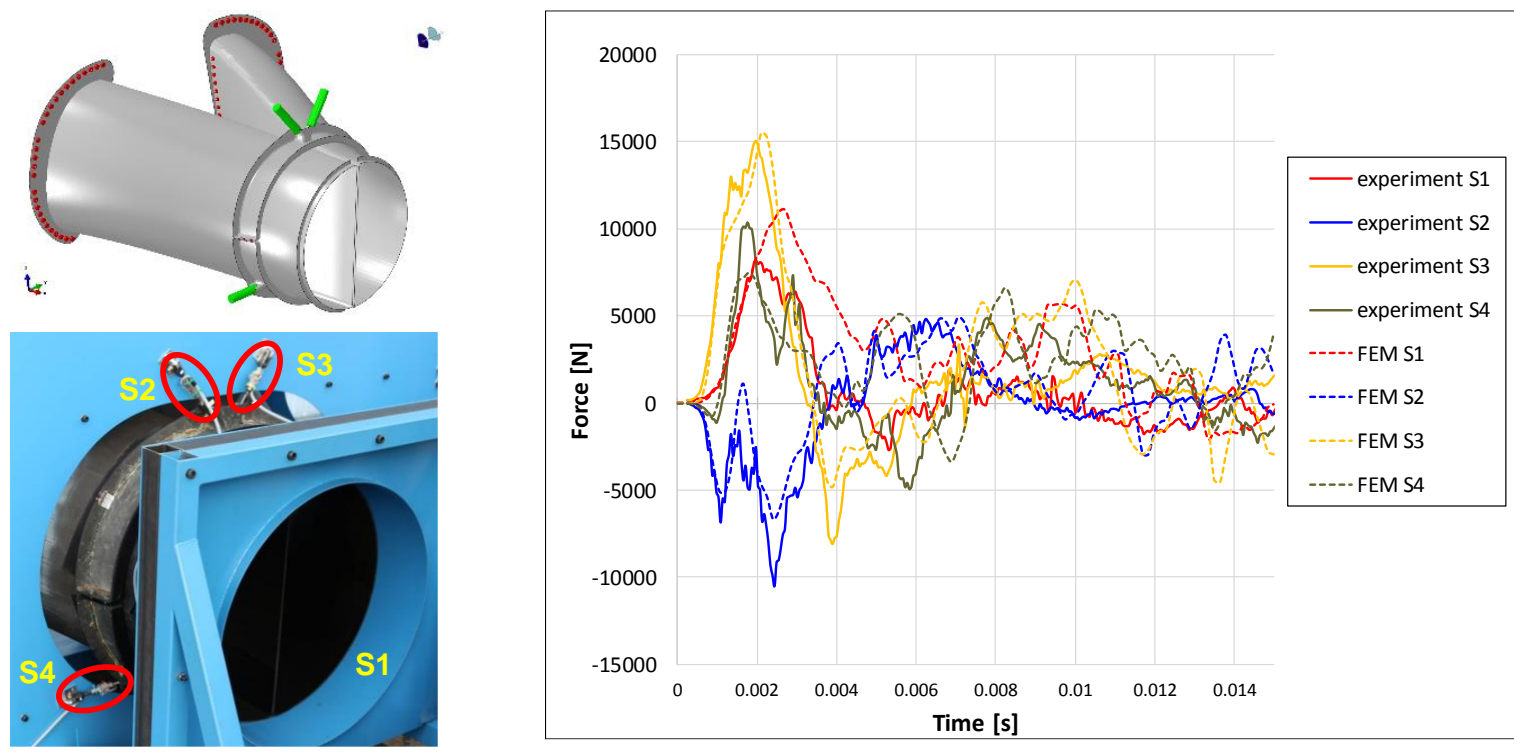

Figure 11: Comparison between experiment measurement (full lines) of attachment rods load during impact and numerical simulation results (dotted lines)

Figure 12 shows comparison between results from strain measurement from FBG sensors and numerical simulation. The data used for comparison are not filtered.
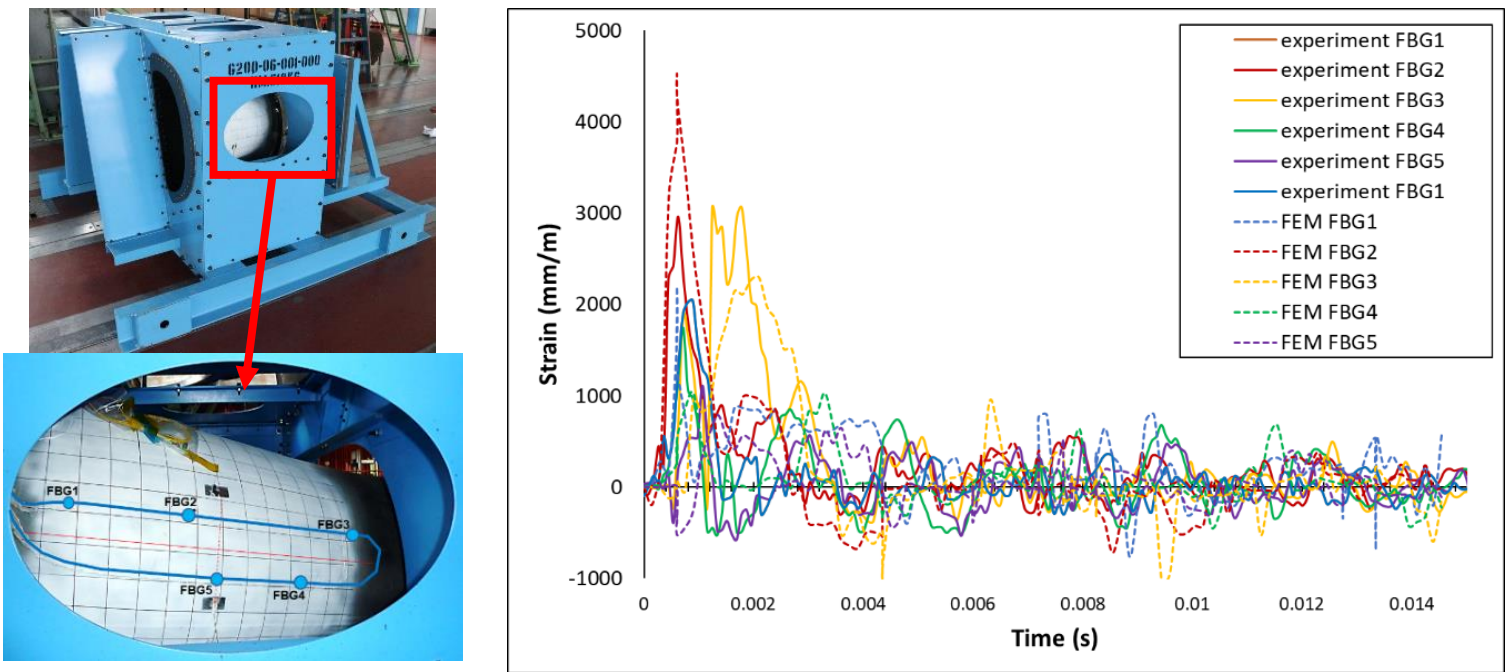

Figure 12: Comparison between strain measurement from FBG sensors (full lines) and numerical simulation (dotted lines)

\section{CONCLUSIONS}

The comparison between test and simulation shows good agreement in prediction of structure behavior. The result of tests confirms impact resistance of proposed composite structure design for real service operation according airworthiness requirements.

The NDT inspection confirm that no damage was observed before and after the tests of full-scale air inlet.

\section{ACKNOWLEDGEMENTS}

This work was supported by the Technology Agency of the Czech Republic (TA ČR) TE02000032 / Advanced Aerostructures Research Centre project. 


\section{REFERENCES}

[1] E. Cleary, R. Dolbeer, S. Wright (2005). Wildlife Strikes to Civil Aircraft in the United States 19902005. Federal Aviation Administration National Wildlife Strike Database.

[2] B. Yang (2013). Safety and Airworthiness Verification of Civil Aircraft Engines. Journal of Mechanical Engineering and Technology, Vol. 1 (3), 92-115.

[3] J. Wilbeck (1978). Impact Behavior of Low Strength Projectiles. Air Force Materials Lab, Air Force Wright Aeronautical Labs, Report No. AFML-TR-77-134, Wright-Patterson AFB, OH.

[4] R. Batra, et al (2012). Damage and failure in low energy impact of fiber-reinforced polymeric composite laminates. Com. Struct., Vol. 94 (2), 540-547.

[5] ASTM D7136M - 07 (2007). Standard Test Method for Measuring the Damage Resistance of a Fibre-Reinforced Polymer Matrix Composite to a Drop-Weight Impact Event.

[6] ASTM F330 -10 (2010). Standard Test Method for Bird Impact Testing of Aerospace Transparent Enclosures.

[7] ASTM F320-05 (2005). Standard Test Method for Hail Impact Resistance of Aerospace Transparent Enclosures.

[8] HexPly ${ }^{\circledR} 8552$ (2017). Product Data http://www.aerospares.hu/files/hexcel/hexply_8552.pdf.

[9] Defence Standard 00-970 (2016). PART 1 Section 4.9, issue 3.

[10] Dvořák, M., Doubrava, K. (2017). Test Results Collection (Demonstrator Test), report CTU 12105/17/29, in Czech

[11] S. Sánchez-Sáez, E. Barbero, C. Navarro (2007). Analysis of the dynamic flexural behaviour of composite beams at low temperature. Computer Science and Technology, vol. 67(11), https://doi.org/10.1016/j.compscitech.2006.12.002, 2616-2632.

[12] ABAQUS 6.14 (2017). Theory manual, http://abaqus.software.polimi.it/v6.14/.

[13] R. Hedayati, M. Sadighi (2015). Bird Strike: An Experimental, Theoretical and Numerical Investigation. Woodhead Publishing, ISBN: 978-0-08-100093-9, Elsevier.

[14] S. Heimbs (2011). Computational Methods for Bird Strike Simulations: A Review. Computers \& Structures, Vol. 89 (23), 2093-2112.

[15] Z. Hashin (1981). Failure criteria for unidirectional fiber composites. ASME Journal of Applied Mechanics, Vol. 47, 329-334.

\section{COPYRIGHT STATEMENT}

The authors confirm that they, and/or their company or organization, hold copyright on all of the original material included in this paper. The authors also confirm that they have obtained permission, from the copyright holder of any third party material included in this paper, to publish it as part of their paper. The authors confirm that they give permission, or have obtained permission from the copyright holder of this paper, for the publication and distribution of this paper as part of the READ 2018 proceedings.

This is an open access article distributed under the Creative Commons Attribution License which permits unrestricted use, distribution, and reproduction in any medium, provided the original work is properly cited. (CC BY 4.0). 